\title{
Epidemiology of Gastrointestinal Parasitism in Small Ruminants in Pudukkottai District, India
}

\author{
S. Rajarajan ${ }^{1 *}$, K.M. Palanivel ${ }^{2}$, M. Geetha ${ }^{2}$ and N. Rani ${ }^{3}$ \\ ${ }^{1}$ Government of Tamil Nadu, ${ }^{2}$ Department of Preventive Medicine, ${ }^{3}$ Department of Veterinary \\ Parasitology, Veterinary College and Research Institute, Namakkal, Tamil Nadu \\ Veterinary and Animal Sciences University, Chennai, India \\ *Corresponding author:
}

\section{A B S T R A C T}

\section{Keywords}

Prevalence, G I parasitism, L3 larva, Sheep, Goats, Risk factors.

Article Info

Accepted: 29 September 2017 Available Online: 10 October 2017
A prevalence study on the gastrointestinal (G.I) parasitism of sheep and goats was carried out during October 2016 to March 2017 in Pudukkottai district, Tamilnadu. A total of 1300 small ruminants comprising of 650 sheep and 650 goats were collected from organized and unorganized farms located in the study region. Out of 1300 faecal samples examined 599(43.00\%) were positive for G.I parasites. The sheep population had higher prevalence of $302(46.46 \%)$ while the goat population had lesser prevalence of 257 (39.53\%). Male sheep had a prevalence of $96(17.17 \%)$ while female sheep had a prevalence of $206(37.05 \%)$. Male goats had a prevalence of $85(15.20 \%$ ) while females had a prevalence of $172(30.76 \%)$. The higher prevalence of G.I parasites were observed in young animals when compared to adult ones. A significant difference was observed in prevalence of G.I parasites with respect to season where in higher prevalence 354 $(54.46 \%)$ were recorded during the wet season while $205(31.53 \%)$ in dry season (summer). The G.I parasites observed were H.contortus, O.columbianum, B.trigonocephalum, S.papillosus, M.expansa and Coccidia species. H.contortus and Coccidia species had the highest prevalence, while M.expansa had the lowest prevalence.

\section{Introduction}

Sheep and goats are the earliest ruminants to be domesticated. They can withstand a period of draught better than any other livestock and they can use those pastures, which cannot be used by other livestock. Sheep and goat rearing plays an important role in the livelihood of poor, small and marginal farmers and provides a major source of income especially through self-employment and guaranteed supplementary household income to the majority of rural farming population of India, since the sheep and goats are the good source of food protein, skin, fiber, manure, etc. and these animals provide an average net income of about ₹ 250/animal to its owner and to the Indian economy as a whole of ₹ 66.109 million annually (Madan,1996). Commonly occurring gastrointestinal parasitism in goats and sheep are Haemonchosis, Strongyloidosis, Oesophagostomiasis, Bunostomiasis, Trichostrongylosis and Coccidiosis. Among these G.I parasites, Haemonchus contortus is the most prevalent and important parasite (Khalafalla et al., 2011). The degree of infestation may be sub-clinical or clinical 
depending on level of parasitic load. Sub clinical infections remain dominant and as such are not recognized by the clinicians and owners. These are responsible for a number of economic losses in a variety of ways as: losses through lower fertility, reduced work capacity, involuntary culling, reduction in feed intake, lower weight gains, reduction in milk and meat production, increased treatment costs and mortality in heavily parasitized animals (Fikru et al., 2006). A proper understanding about the epidemiology of G.I parasitism is a prerequisite for the rational designing of the effective preventive and control measures against these dreadful G.I parasitic diseases. Keeping the same in view the present study was taken into consideration in order to explore the epidemiology of various G.I parasites infesting the small ruminants in Pudukkottai district of Tamilnadu and various associated risk factors for an effective management.

\section{Materials and Methods}

\section{Study area and duration}

The study was conducted in sheep and goats of Pudukkottai district, Tamilnadu (India) during October 2016 to March 2017.

\section{Study animals}

A total of 1300 small ruminants including 650 sheep and 650 goats were considered during the study which includes apparently healthy and clinically affected sheep and goat of organized and unorganized farms located in the study region including Government farms.

\section{Study methodology}

\section{Study type and procedure}

Faecal samples were collected at random along with relevant epidemiological data according to the species, age, sex, management, climatic condition, flock size, health status of the animals, etc... The faecal samples were collected appropriately from the rectum using protective disposable gloves and the animals were subjected to clinical examination before collection of samples, the health status of the animals (ocular mucous membrane, presence of sub-mandibular swelling, dag scoring, body condition and coat condition) were examined for analysis.

All the samples were subjected to gross examination for colour, consistency, for presence of any adult worms and laboratory examination such as direct smear/floatation/sedimentation techniques to enumerate the prevalence of G.I parasitism in small ruminants. Positive samples were subjected to quantitative examination using Mc Master coprological diagnostic technique to assess the intensity of G.I parasitism (EPG/OPG). Micrometry methods were used to measure the size of eggs for speciation of G.I parasites. Coproculture techniques were employed to differentiate the $\mathrm{L}_{3}$ larvae for speciation of G.I parasites on the basis of morphological and morphometric characteristics. Results of these techniques were analyzed and interpreted. Epidemiological data such as age, sex, species, farm size, season, health status of the animals, etc... were correlated with the prevalence of G.I parasitism to develop a clinical scoring system.

\section{Results and Discussion}

Of these 1300 sheep and goats examined, the parasites identified were, Haemonchus contortus, O.columbianum, B.trigonocephalum, Strongyloides papillosus, Amphistomes, Moniezia expansa and Eimeria species, depicted (Table 1). A total of 559 animals were found infected with one or more G.I parasite species, it reveals the overall 
prevalence as (43.00\%) with $(39.53 \%)$ and $(46.46 \%)$ in sheep and goats respectively (Table 2). The study also observed higher prevalence in females (46.29\%) and young ones $(46.88 \%)$ as compared to males (34.68\%) and adults (40.94\%) in sheep and goats respectively. Similarly an association was found between the prevalence and flock size, wherein the prevalence was higher in larger flock $(46.47 \%)$ as compared to smaller flocks $(38.81 \%$,$) . There were statistically$ significant differences in prevalence of parasites with respect to season; it was observed that the infection rate was higher in wet season $(54.46 \%)$ than in the dry season (31.53) in both the host species.

The study further revealed that health status of the animals has a major effect on the prevalence of helminth infections where in it was observed that the animals which were healthy had less infection $(32.55 \%)$ with the average EPG/OPG level of $(<1000 / 10,000)$ as compared to those which were comparatively weak $(67.44 \%)$ with the average EPG/OPG of (> 1000/>10,000) (Table 3). Analyzing the above factors a clinical scoring system has been developed for easy understanding of the epidemiology of G.I parasitism in small ruminants (Table 4). According to the above findings a clinical scoring system has been developed (Table 5).

The present investigation revealed that the G.I parasitic infection in sheep and goats occur throughout the district. It also disclosed that regardless of the environmental conditions, species, age, sex of the host, in this region are infected with a variety of the G.I parasites. The various parasites recovered during the study have also been reported from the other agro climatic regions of the same state $(\mathrm{TN})$, as well as from different parts of the country, having almost same geographical locations and environmental conditions (Palanivel et al., 2012).
The higher prevalence in goats as compared to sheep is in agreement with reports of (Thangathurai et al., 2002). This could be due to slow or less development of immunity in goats to gastrointestinal parasites compared with the situation in the sheep, the later faced prolonged challenge over generations, but in goats, the less availability of sufficient browsing area and expansion of crop agriculture forced them to graze with the other species that had good resistance. In addition goats in this study region are managed under extensive pastoralism in which large number of animals is kept together. This could increase the degree of pasture contamination leading to higher prevalence rate (Fikru et al., 2006). The higher prevalence of nematodes than trematodes and cestodes is in contest with many reports all over the world, (Patel et al., 2001 and Sissay et al., 2006).

The present study further described that sex of animals show an association with the prevalence of the parasites, the higher prevalence in females than their counter partners may be due to some physiological peculiarities of the female animals, which usually constitute stress factors thus, reducing their immunity to infections and also the females happen to be lactating which leads to weakness or malnutrition. These findings agree with the reported findings of (Blood \& Radostits, 2000). The significantly higher prevalence in wet season than that of the dry season is in consent with many reports around the world (Gupta et al., 2003). This could be due to the existence of a direct relationship between prevalence with rainfall, humidity and temperature. The presence of sufficient rainfall and moisture during wet season favored the survival of infective larvae in pasture and higher probability of uptake of the infective larvae leading to higher prevalence rate (Sissay et al., 2006).Similarly the higher prevalence recorded in younger animals as 
compared to the adult ones are in agreement with most literatures (Dunn, 1978, ShahFischer et al., 1989 and Nganga, 2004) from different corners of the world. This could be due to the fact that younger animals are more susceptible to infections than adults. Adult animals may acquire immunity to parasites through frequent challenge and expel the ingested parasites before they establish infection; (Dunn, 1978 and Shah-Fischer et al., 1989). The reason for higher prevalence in larger flock size, as compared to smaller flock size could be that the possibility of harboring the infection is high in case of larger flocks because of the larger population. The possible reason for slightly higher prevalence in weak animals of both the host species could be that these animals usually have a comparatively weak immune system which does not fight with the infections to the same extent as that of a healthy animal's immune system (Kuchai, 2011). In the present study, combined the five points will monitor anemia, body condition, diarrhea, submandibular edema and coat condition, which represent the clinical signs normally seen in parasitized animals. With each point, there is a scale. Animals that have overall scores on the "good" side do not need to be dewormed. Conversely, animals with "bad" scores would most likely benefit from deworming, followed by close monitoring for several months. For animals that have mixed scores (some good, some bad), we use our best judgment. If they are not as robust as other animals in the herd, it may be beneficial to deworm them (Table 5). Similar findings reported by Van Wyk (2002).

Table.1 Prevalence of G I parasitism on the basis of type of G.I parasite

\begin{tabular}{|l|c|c|}
\hline G.I parasite & No Positive & Prevalence \\
\hline H.contortus & 273 & $21.00 \%$ \\
\hline O.columbianum & 17 & $1.30 \%$ \\
\hline B.trigonocephalum & 28 & $2.15 \%$ \\
\hline S.papillosus & 68 & $5.23 \%$ \\
\hline Amphistomes & 20 & $1.53 \%$ \\
\hline M.expansa & 16 & $1.23 \%$ \\
\hline Eimeria species & 137 & $10.50 \%$ \\
\hline Mixed infection & 48 & $3.69 \%$ \\
\hline
\end{tabular}

Table.2 Prevalence of G I parasitism on the basis of species of the host

\begin{tabular}{|l|c|c|c|}
\hline \multicolumn{1}{|c|}{ Species } & $\begin{array}{c}\text { No of faecal samples } \\
\text { Examined }\end{array}$ & No Positive & Prevalence \\
\hline Sheep & 650 & 302 & $46.46 \%$ \\
\hline Goat & 650 & 257 & $39.53 \%$ \\
\hline Total & $\mathbf{1 3 0 0}$ & $\mathbf{5 5 9}$ & $\mathbf{4 3 . 0 0 \%}$ \\
\hline
\end{tabular}


Table.3 Prevalence of G I parasitism on the basis of Sex, Age, Flock size and Season of the host

\begin{tabular}{|c|c|c|c|c|}
\hline \multirow{2}{*}{ Factors } & Parameters & $\begin{array}{c}\text { No of faecal } \\
\text { samples } \\
\text { Examined }\end{array}$ & No Positive & Prevalence \\
\hline \multirow{3}{*}{ Sex } & Male & 369 & 128 & $34.68 \%$ \\
\cline { 2 - 5 } Age & Female & 931 & 431 & $46.29 \%$ \\
\cline { 2 - 5 } & Young & 450 & 211 & $46.88 \%$ \\
\hline \multirow{3}{*}{ Flock size } & Adult & 850 & 348 & $40.94 \%$ \\
\cline { 2 - 5 } Season & Small & 590 & 229 & $38.81 \%$ \\
\cline { 2 - 5 } & Large & 710 & 330 & $46.47 \%$ \\
\cline { 2 - 5 } & Wet & 650 & 354 & $34.46 \%$ \\
\cline { 2 - 5 } & Dry & 650 & $\mathbf{5 5 9}$ & $\mathbf{4 3 . 0 0 \%}$ \\
\hline
\end{tabular}

Table.5 Clinical scoring system for G.I parasitism in small ruminants

\begin{tabular}{|c|c|c|c|c|c|}
\hline $\begin{array}{c}\text { Check } \\
\text { point }\end{array}$ & Observation & $\begin{array}{c}\begin{array}{c}\text { Scores } \\
\text { need } \\
\text { attention }\end{array} \\
\end{array}$ & $\begin{array}{c}\text { Average } \\
\text { EPG/OPG }\end{array}$ & Scores & Possibilities \\
\hline Eye & $\begin{array}{c}\text { Anaemia } \\
(1-5) \\
\text { FAMACHA } \\
\text { CARD } \\
\end{array}$ & $1-3$ & $>1000$ & ++ & $\begin{array}{l}\text { Haemonchus spp, } \\
\text { Bunostomum spp, and } \\
\text { other worms, etc... }\end{array}$ \\
\hline Back & $\begin{array}{c}\text { BCS } \\
(1-5) \\
\text { BCS CARD }\end{array}$ & $1-3$ & $>1000$ & ++++ & $\begin{array}{c}\text { Trichostrogyle spp, } \\
\text { Oesophagostomum } \\
\text { spp, and other worms } \\
\text { and etc... } \\
\end{array}$ \\
\hline Tail & $\begin{array}{c}\text { Faecal soiling } \\
(1-5) \\
\text { DAG SCORE } \\
\text { CARD }\end{array}$ & $1-3$ & $>1000 />10000$ & + & $\begin{array}{c}\text { Trichostrogyle spp, } \\
\text { Coccidia spp, } \\
\text { Oesophagostomum } \\
\text { spp, and other worms, } \\
\text { etc... }\end{array}$ \\
\hline Jaw & $\begin{array}{l}\text { Soft swelling } \\
(1-5) \\
\text { BOTTLE JAW }\end{array}$ & $1-3$ & $>1000 />10000$ & +++++ & $\begin{array}{l}\text { Haemonchus spp, } \\
\text { Bunostomum spp, } \\
\text { Liver flukes, Coccidia } \\
\text { spp, and other worms } \\
\text { and causes. }\end{array}$ \\
\hline Coat & $\begin{array}{l}\text { Coat condition } \\
(1-3) \\
\text { COAT SCORE }\end{array}$ & $1 \& 2$ & $>1000$ & +++ & $\begin{array}{l}\text { Haemonchus spp, } \\
\text { Trichostrogyle spp, } \\
\text { Coccidia spp, External } \\
\text { parasites and other } \\
\text { causes. }\end{array}$ \\
\hline
\end{tabular}


Table.4 Prevalence of G I parasitism on the basis of health status and EPG/OPG levels

\begin{tabular}{|l|c|c|c|c|}
\hline $\begin{array}{c}\text { Health } \\
\text { status }\end{array}$ & $\begin{array}{c}\text { No of } \\
\text { samples } \\
\text { Examined }\end{array}$ & Average EPG/OPG & EPG/OPG Range & Prevalence \\
\hline Good & 182 & $<1000 /<10,000$ & $380-980 / 1,000-9,000$ & $32.55 \%$ \\
\hline Moderate & 280 & $>1,000-2000 />10,000$ & $1,020-1,980 / 11,000-49,000$ & $50.08 \%$ \\
\hline Poor & 97 & $2,000-5,000 />50,000$ & $2,010-4,900 / 50,000-70,000$ & $17.35 \%$ \\
\hline Total & $\mathbf{5 5 9 / 1 , 3 0 0}$ & - & - & $\mathbf{4 3 . 0 0 \%}$ \\
\hline
\end{tabular}

Most livestock are scored on a scale 1 to 5 , with 1 being emaciated and 5 being fat. When using 1-5 scale, an average scores of 3 works well for most animals. Realistically, members of the herd should always fall between scores of 2 and 4 . Extreme scores of 1 and 5 should be avoided, as they are associated with decreased production and health problems. Animals with scores of 1 and 2 are good candidates for deworming and an animal with a score of 3 should only be dewormed if other scores fall into the "bad" category Paula Menzies (2007).

\section{General guidelines for treatment decisions}

A "negative" test result is usually not the goal, except in the case of lungworm testing.

< 1000 EPG: Low level: may or may not require treatment, depending on parasite and clinical symptoms.

> 1000 EPG: Moderate level: may require treatment (especially lactating females and young stock).

>2000 EPG: High level: likely associated with clinical symptoms Treatment indicated in most cases (Hensen \& Perry, 1994).

$<10,000$ OPG: Low level, Up to 50,000: Moderate,

Above 50,000: Severe infection.

In conclusion, the present study emphasize that it is beyond the doubt that the sheep and goats of Pudukkottai district are infected by a large number of G.I parasites which could be responsible for economic losses in a variety of ways, therefore efforts should be made to control G.I parasitism, which requires a detailed knowledge of these parasites and it is believed that the present study will provide some help for the same. The study also indicates that season, sex, age, flock size and health status of the animal appears to be the major limiting factors for the prevalence of G.I parasites. To create awareness among the farmers on methods of transmission and effect of these parasites on the productivity of the animals studies should be carried out from time to time.

\section{Acknowledgement}

The authors thank the owners of the farms for their co-operation in conducting this study and the University authorities for providing necessary facilities to carry out this investigation work. The authors declare that they have no competing interest for publishing the data.

\section{References}

Blood, D.C. and Radostits, O.M. 2000. Veterinary Medicine, 7th ed. Balliere Tindall London.

Dunn, A.M. 1978.Veterinary Helminthology, 2nd edition London. William Heinemann Medical Books. 
Fikru, R., Teshale, S, Reta, D. and Yosef. K. 2006. Epidemiology of gastrointestinal parasites of ruminants in Western Oromia, Ethiopia", Int. J. Appl. Res. Vet. Med., 51- 57.

Gupta, S.K., Chaudhri, S.S., and Poonia, J.S. 2003. Preliminary report of closantel resistance against Haemonchus contortus in sheep of western Haryana. Indian J, Anim. Sci., 1024-1026.

Khalafalla, R.E., Elseify, M.A. and Elbahy, N.M. 2011. Seasonal prevalence of gastrointestinal nematode parasites of sheep in northern region of Nile Delta, Egypt. Parastol. Res., 337-340.

Kuchai, J.A., Chishti, M.Z., Zaki, M.M., Ahmad, J., Rasool, Dar, S.A., and Tak, H. 2011. Epidemiology of helminth parasites in small ruminants of Ladakh, India. J. Anim. Feed Res., 1(5): 239242.

Madan, M.L. 1996. Sustainable parasite control in small ruminant. Proceedings of workshop, Bogor, Indonesia, 22-25, 13-20.

Nganga, C.J., Maingi, N., Munyua, W.K., and Kanyari, P.W. 2004. Epidemiology of helminth infection in ruminants of semiarid area of Kenya. Ondestepool J. Vet. Res., 71(3): 219-226.

Palanivel, K.M., Rishikesavan, R., Sureshkumar, K. and H. Gopi. 2012.
Epidemiology of parasitic infection in madras red sheep in Tamil Nadu. Int. $J$ F A V Sci., 2(3): 140-145.

Patel, M.D., Nauriyal, D.S, Hasnani, J.J. and Gupta, R.S. 2001. Prevalence of gastrointestinal parasitism in goats maintained under semi intensive am field management systems. Indian $J$. Vet. Med., 21: 99- 101.

Paula Menzies. 2007. Control of Gastrointestinal Parasites in Sheep and Goats. University of Guelph, 1-11.

Shah-Fischer, M., and Say, R. 1989. Manual of Tropical Veterinary Parasitology. CAB International, The Technical Center for Agricultural and Rural Cooperation (CTA).

Sissay, M.M., Uggla, A. and Waller, P.J. 2006. Epidemiology and seasonal dynamics of gastrointestinal nematode infections of sheep in a semi-arid region of eastern Ethiopia. Vet. Parasitol., 143: 311-321.

Thangathurai, R. and Rao, D.G.K. 2002. Occurrence of enteric parasitism of goats in Bidar Region (Karnataka). Indian J. Animal Health, 41: 151-152.

Van Wyk, J.A., and Bath, G.F. 2002. The FAMACHA $\odot$ system for managing haemonchosis in sheep and goats by clinically identifying individual animals for treatment. Vet. Res., 33: 509- 529.

\section{How to cite this article:}

Rajarajan, S., K.M. Palanivel, M. Geetha and Rani, N. 2017. Epidemiology of Gastrointestinal Parasitism in Small Ruminants in Pudukkottai District. Int.J.Curr.Microbiol.App.Sci. 6(10): 4924-4930. doi: https://doi.org/10.20546/ijcmas.2017.610.464 